See discussions, stats, and author profiles for this publication at: https://www.researchgate.net/publication/335524434

\title{
Metacognitive Self-Assessment Scale: psychometric properties and clinical implications
}

Article in Applied Neuropsychology: Adult · October 2019

Dol: 10.1080/23279095.2019.1671843

\section{CITATIONS}

10

5 authors, including:

Bruno Faustino

University of Lisbon

51 PUBLICATIONS 120 CITATIONS

SEE PROFILE

Jorge Oliveira

Universidade Lusófona de Humanidades e Tecnologias 109 PUBLICATIONS 961 CITATIONS

SEE PROFILE
207

António Branco Vasco

University of Lisbon

74 PUBLICATIONS 540 CITATIONS

SEE PROFILE

Paulo Jorge Ferreira Lopes

Universidade Lusófona de Humanidades e Tecnologias

63 PUBLICATIONS 471 CITATIONS

SEE PROFILE

Some of the authors of this publication are also working on these related projects:

Clinical Psychology and Psychotherapy View project

Affective Neuroscience and Personality View project 


\section{Metacognitive self-assessment scale: psychometric properties and clinical implications}

\section{Bruno Faustino, António Branco Vasco, Jorge Oliveira, Paulo Lopes \& Isabel Fonseca}

To cite this article: Bruno Faustino, António Branco Vasco, Jorge Oliveira, Paulo Lopes \& Isabel Fonseca (2019): Metacognitive self-assessment scale: psychometric properties and clinical implications, Applied Neuropsychology: Adult

To link to this article: https://doi.org/10.1080/23279095.2019.1671843

册 Published online: 24 Oct 2019.

Submit your article to this journal \lceil

Q View related articles $\sqsubset$

View Crossmark data \lceil 


\title{
Metacognitive self-assessment scale: psychometric properties and clinical implications
}

\author{
Bruno Faustino $^{\mathrm{a}, \mathrm{b}} \mathbb{D}$, António Branco Vasco ${ }^{\mathrm{a}}$ (D) , Jorge Oliveira ${ }^{\mathrm{b}}$ (D) ${\text { Paulo } \text { Lopes }^{\mathrm{b}} \text { (D) , and Isabel Fonseca }}^{\mathrm{a}}$ \\ ${ }^{\mathrm{a} F a c u l d a d e}$ de Psicologia, Universidade de Lisboa, Lisboa, Portugal; ${ }^{\mathrm{b}}$ Faculdade de Psicologia e Ciências da Vida da, Universidade Lusófona \\ de Humanidades e Tecnologias, Lisboa, Portugal
}

\begin{abstract}
Metacognition is a higher-order psychological construct that has been conceptualized as the ability to identify and describe mental states, beliefs, and intentions of self and others. The Metacognition Self-Assessment Scale (MSAS), was developed to assess different functions of metacognition, being a potential asset in fields such as psychotherapy and clinical neuropsychology. However, a reliability and validity study is still lacking, as well, the study with other related metacognitive constructs. This research describes the psychometric analysis of the MSAS in a crosssectional design and the study of the relationship between metacognitive functions, meta-beliefs and cognitive fusion. The sample comprised 194 participants from the general population (76\% women), with an average age of 32 years old. Exploratory factor analysis, Cronbach alpha, testretest, and validity procedures through bivariate correlations with convergent/divergent measures were conducted. The scale showed satisfactory psychometric properties with good internal consistency along with appropriate convergent/divergent validity. Metacognition and cognitive fusion were negatively correlated, while negative meta-beliefs and mastery predicted the variance of cognitive fusion. Decentering-differentiation factor correlated negatively with cognitive fusion and personal discomfort. These results suggest that MSAS may be a reliable tool to assess metacognition in the Portuguese population. Clinical implications are discussed.
\end{abstract}

\section{KEYWORDS}

Cognitive fusion; metacognition; meta-beliefs psicometrics; self-report

\section{Introduction}

Metacognition is a general term to define an interconnected psychological and neuropsychological set of abilities, that allow humans to understand one's own and the others' states of mind, beliefs, wishes, intentions and actions (Pedone et al., 2017; Semerari et al., 2003). It is also related to mental abilities such as self-reflection, decentering and mastery (Dimaggio, Semerari, Carcione, Nicolò, \& Procacci, 2007).

Researchers had studied similar "mind-reading" abilities within different theoretical perspectives, using different names and lexicon (Pedone et al., 2017). Similar and overlapping mental functions can be found in research fields as the theory of mind (Premack \& Woodruff, 1978; Frith \& Frith, 2006), social cognition, (Lories, Dardenne, \& Yzerbyt, 1998), alexithymia (Nemiah, Freyberger, \& Sifneos, 1976), affect consciousness (Solbakken, Hansen, Havik, \& Monsen, 2012) and mentalization (Bateman, Bolton, \& Fonagy, 2013; Fonagy, Gergely, Jurist, Elliot, \& Target, 2002). Pedone et al. (2017), emphasize the common factors underlying these constructs, such as the operation of mental contents and cognitive functions as described in the Metacognitive MultiFunction Model (MMFM, Semerari et al., 2003).

MMFM regards metacognition as a set of skills intended as functions (Pedone et al., 2017). This model stresses the functional aspect of metacognition, where operations are necessary to (1) identify and describe mental states regarding self and others based on internal experience and observable behavior, (2) reflect and reasoning about diverse mental contents such as mental states, (3) use mental information for complex decision making, problem-solving and cope with suffering (Carcione et al., 2010). Thus, metacognition has been studied also in neuroscience (Brunet-Gouet et al., 2011; Raposo et al., 2010).

The neural basis of metacognition and theory of mind have been related to mirror neurons in the orbitofrontal cortex (Gallese, Fadiga, Fogassi, \& Rizzolatti, 1996) and the lateral prefrontal cortex (Fleming \& Dolan, 2012), which are responsible for mimic behavior, develop empathy, and understand the emotional states of others (Praszkier, 2016). Moreover, Fleming and Dolan (2012), propose that metacognitive processes may be related to cognitive control, by a neural network in which dorsolateral and anterior prefrontal cortical sub-regions interact with interceptive cortices (cingulate and insular) to promote accurate judgments of performance and decision making.

Shimamura (2000), stated that metacognition regulation involves attention, conflict resolution, error correction, inhibitory control and emotion regulation, being these processes mediated by a neural circuit involving middle frontal 
brain regions (anterior cingulate and orbitofrontal cortex). Therefore, it is suggested that may be an overlap between metacognition, working memory, executive control, inhibition and frontal lobe functioning (Shimamura, 2000).

Comparing the MMFM with prior psychological models as the Self-Regulatory Executive Function SREF, (Wells, 2000; Wells \& Mathews, 1994), the MMFM has distinctive features because it focuses on mental processes and operations, instead of mental contents (Semerari et al., 2003). In contrast, SREF regards metacognition as a set of higherorder or meta-beliefs about one's own mental contents, which modulate attentive processes associated with preoccupation and worry (Wells \& Mathews, 1994). Psychological research has shown that metacognitive beliefs may have a precipitant role in psychological suffering (Wells, 2000). However, a study between these two models is lacking.

Mentalization and MMFM overlap in explicit cognitive process on self/other dimensions, but MMFM differs from mentalization because it defines specific functional processes that operate in states of mind (Pedone et al., 2017). Mentalization is a multicomplex construct defined broadly as thought about thinking (Fonagy et al., 2002). Research has consistently associated deficits in mentalization with Borderline Personality Disorder (Bateman et al., 2013).

There is growing evidence that metacognitive dysfunctions play a key role in psychopathology, due to impairments on understanding one's own and other's internal experience, with implications in the development of integrated and stable self-self and self-other representations (Dimaggio et al., 2007; Dimaggio, Montano, Popolo, \& Salvatore, 2015). In this sense, metacognitive deficits are associated with schizophrenia (Dimaggio \& Lysaker, 2010), emotional disorders (Wells, 2000), personality disorders (Dimaggio et al., 2015), autism spectrum disorders (Grainger, Williams, \& Lind, 2014), learning disabilities (Lucangeli, Cornoldi, \& Tellarini, 1998) and executive dysfunctions (Lysaker et al., 2008). Also, metacognitive deficits has been associated with poor social functioning (Bo, Kongerslev, Dimaggio, Lysaker \& Abu-Akel, 2015), difficulties in affect regulation (Harder \& Folke, 2012) and neurocognitive impairment on verbal and visual memory and speed of processing (Nicolò et al., 2012). These evidences highlight the importance of metacognition as a relevant clinical construct. Thus, metacognition may be viewed with a transdiagnostic perspective due to it's neurobiology and symptomatic expression across different clinical phenotypes (Gumley, 2011).

Several methods exist to assess metacognition, such as discourse analysis, interviews, and questionnaires (Pedone et al., 2017). However, neuropsychological assessment typically uses performance tests, rather than self-reporting measures, where the individual is tested for the ability to be assessed. It is assumed that cognitive abilities are better evaluated by performance tests than by self-reported measures, due to social desirability bias (Lezak, 2015). Thus, one important aspect of neurocognitive assessment is the diagnostic precision of the instruments to detect neurocognitive impairment in different clinical populations (Faustino, Oliveira, \& Lopes, 2019).
The main measures available in the Portuguese language to assess metacognition are the Metacognitive Questionnaire - 30 (MCQ-30, Wells, 2000, translated and adapted by Dinis \& Pinto-Gouveia, 2011) and the Metacognitive Awareness Inventory (MAI, Schraw \& Dennison, 1994, translated and adapted by Bártolo-Ribeiro, Simões, \& Almeida, 2016). However, these self-report measures are focused on metacognitive mental contents, instead of a metacognitive structure or functions. Thus, validation procedures focused on interpersonal domains may also differentiate self-self, from self-other functions, such as the Interpersonal Reactivity Index (Limpo, Alves, \& Castro, 2010).

Bernstein et al. (2015), described decentering-related constructs as a set of common mental abilities that may share the same underlying processes. Some constructs are cognitive defusion, cognitive distancing, meta-cognitive awareness or self-as-context. In MMFM, decentering is also a core function of metacognition (Semerari et al., 2003). Similarly, Bernstein et al., (2015), describes a metacognitive model of decentering with three related processes as meta-awareness (awareness of subjective experience), disidentification from internal experience (the experience of internal states as separate from one's self) and reduced reactivity to thought content (reduced effects of thoughts on other mental processes). Author's states that cognitive fusion may be a decenteringrelated construct because it reflects increased reactivity to thought content. Nevertheless, research is still lacking to better understand this relationship (Bernstein, Hadash, \& Fresco, 2019).

Cognitive fusion may be a part of a dysfunctional process that contributes to psychological inflexibility, maintained by strict verbal rules, where individuals persevere in the same mental contents, which causes psychological suffering (Gillanders et al., 2014; Hayes, Strosahl, \& Wilson, 2011). Cognitive fusion is regarded as a construct from Acceptance and Commitment Therapy (ACT, Hayes et al., 2011), which is associated with anxiety, depression and interpersonal problems (Gillanders et al., 2014). Therefore, due to the rigidity of thought, the structural abilities of identification, differentiation, integration, decentering, and mastery may be compromised. It will be interesting to study whether metacognition is associated with such processes of cognitive fusion. To our best knowledge, this is the first study that explores the relationship between metacognition and cognitive fusion. Moreover, our research described the psychometric analysis of MSAS, through Exploratory Factor Analysis (EFA), test-retest, convergent validity, divergent validity and discriminant validity. Also, we explored the relationships between metacognitive functions, meta-beliefs and cognitive fusion.

\section{Method}

\section{Participants}

Data were analyzed from 194 participants collected from the general population. Participants were recruited in a Portuguese university in Lisbon and through online social media (i.e. Facebook, LinkedIn). Participants completed a 
short-form for sociodemographic data along with four selfreport scales. Exclusion criteria were: age $<18$ and $>80$, non-Portuguese speaker and to have a diagnosis of neurological disorders.

From the 194 participants, 47 (24.2\%) were male, and $147(80.6 \%)$ female, with an average age of 32 years $(S D=$ 12.63, ranging from 19 to 65). Most participants had completed secondary education, were Portuguese (95\%), and were single in their marital status (37\%). From the total sample, $88.7 \%$ were not engaged in any psychological treatment and $11.3 \%$ were in psychotherapy or have a selfreported diagnosis. We used these participants and computed a subclinical sample, based on self-reported diagnosis where $11.3 \%$ of individuals $(n=6)$ had depressive related disorders 3 individuals had anxiety related disorders and 3 individuals had attention deficit hyperactivity disorder.

\section{Materials}

\section{Metacognition Self-Assessment Scale (MSAS)}

The MSAS (Pedone et al., 2017) was developed from the MMFM (Semerari et al., 2003), and belongs to a group of validated metacognition assessment tools, the Metacognition Assessment Scale (MAS, Semerari et al., 2003), and the Metacognition Assessment Interview (MAI, Pellecchia et al., 2015; Semerari et al., 2012). The MSAS is a self-report measure with 18 items intended to assess MMFM sub-functions. It is scored in a five-point Likert scale ( $1=$ never, $2=$ rarely, $3=$ sometimes, $4=$ frequently, $5=$ almost always), with a raw score that ranges from 18 to 90 . High scores indicate better metacognitive self-evaluation on metacognitive abilities. According to Pedone et al. (2017) the MSAS was developed to measure five abilities of metacognition: (1) monitoring, (2) differentiation, (3) integration, (4) decentering and (5) mastery. These five abilities are integrated into three higher-order dimensions: (a) reflection on one's own mental states (self-self-domain: understanding one's own mind - UM), (b) reflection on other's mental states (selfother domain: understanding others mind - UOM) and (c) coping with psychological suffering and interpersonal problems (mastery - M). The internal consistency in the current study was considered acceptable (.88)

In the original study, the authors have found a fourfactor structure for the MSAS: (1) the first factor capturing monitoring and integration (self-self-reflexivity), (2) the second factor capturing differentiation and decentering, (3) the third factor depicting the understanding of other's mind (self-other) and (4) the fourth factor involving regulation and control abilities (mastery).

In the current study, the items were translated and adapted to the Portuguese language by the researchers. The back-translation procedure was then carried out by an independent bilingual expert. After an expert agreement, the MSAS Portuguese version was administered to 10 independent individuals in a pilot study. The final adjustments were made to the final version used in the current study.

\section{Metacognitions Questionnaire (MCQ - 30)}

The MCQ-30 (Wells \& Cartwright-Hatton, 2004, translated and adapted to the Portuguese language by Dinis \& PintoGouveia, 2011), is a self-report scale with 30 items measured on a four-point scale, assessing different dimensions of metacognitive beliefs (beliefs about thinking, or metabeliefs). The items are organized in a five-factor structure: (1) positive beliefs about worry; (2) negative beliefs about the controllability of thoughts and corresponding danger; (3) cognitive confidence; (4) need to control thoughts, and (5) cognitive self-consciousness. The internal consistency in the current study through Cronbach's alpha was considered $\operatorname{good}(\alpha=.98)$.

\section{Interpersonal Reactivity Index (IRI)}

The IRI (Davis, 1980, translated and adapted to Portuguese by Limpo et al., 2010), is a self-report measure with 28 statements about feelings and thoughts that individuals may or may not have experienced. The items are rated on a five-point Likert scale from 0 to 4 . This questionnaire assesses four dimensions that reflect empathic concern, personal discomfort, fantasy, and perspective taking. The internal consistency in the current study was considered as acceptable $(\alpha=.67)$.

\section{Cognitive Fusion Questionnaire (CFQ)}

The CFQ (Gillanders et al., 2014, translated and adapted by Pinto-Gouveia, Dinis, Gregório, \& Pinto, 2013) is a selfreport measure comprising 7 items that are rated on a seven-point Likert scale $(1=$ never true to $7=$ always true). The higher scores reflect higher cognitive fusion, which is the degree that thoughts are "fused" with the self. The internal consistency in the current study was considered as acceptable $(\alpha=.88)$.

\section{Procedures}

This study was approved by an ethics committee of the host institution where the study was conducted. After informed consent, the participants completed the evaluation protocol that comprised the sociodemographic form along with the four self-report scales. The participants were asked to complete the forms individually and the contact email was also asked for the participants that agree with the retest assessment. Then, after 4 weeks, they were contacted again by email for the test-retest procedure. No monetary compensation was given for participation in the study.

\section{Data analysis}

Reliability and validity were assessed through the following procedures: (1) Exploratory factor analysis to explore the factorial structure of MSAS; (2) Cronbach's alpha to assess internal consistency; (3) Pearson product-moment correlation coefficient to test convergent and divergent validity between MSAS, MCQ-30 and IRI; (4) $t$-test for independent 
samples was used to distinguish between individuals who scored high vs. low on metacognitive skills for evidence of discriminant validity; and (5) Stepwise regression analysis to test the effects of metacognition on cognitive fusion. The statistical analyses were performed with IBM SPSS Statistics version 24.

\section{Results}

\section{Factor structure}

An Exploratory Factor Analysis (EFA) was used to explore the factor structure of the MSAS. The sample size exceeds the rule of thumb of 10 subjects per item, fulfilling this criterion (Pestana \& Gageiro, 2008).

The factors with eigenvalues higher than 1 were extracted, and rotation was done through the varimax procedure. Four factors were extracted that explained $60.34 \%$ of the total variance. Items loadings below .40 were removed. The solution converged in 5 interactions. The Kaiser-MayerOlkin measure presented was .850 revealing good correlations between variables (Pestana \& Gageiro, 2008). The Bartlett sphericity test was also statistically significant $\left[\chi^{2}\right.$ $(190,412)=1454,865, p<.000]$, which reveals appropriate associations between variables (Pestana \& Gageiro, 2008).

The first factor accounted for $35.57 \%$ of the variance which comprised items $1,2,3,6$ and 7 , resembling the domain understanding one's own mind with the abilities of monitoring, identification, integration and relating variables. The second factor accounted for 9,95\% of the variance which comprised items $4,5,11,12,13,14$, and it expresses the domain related to decentering - differentiation, with the abilities of decentering (items 11, 12 and 13), differentiating from understanding one's own mind domain (items 4 and 5) and mastery, from mastery theoretical factor (item 14). The third factor accounted for $7.69 \%$ of the variance and is composed of items 15,16,17 and 18, resembling the abilities related to mastery (Table 1). The fourth factor accounted for $7.12 \%$ of the variance and is composed of items 8,9 and 10 , reflecting the domain understanding other's mind, comprising the abilities of identification, decentering and relenting variables.

Therefore we considered factor 1 as understanding one's own mind (self-self reflexivity), factor 2 as decentering differentiation (critical distance), factor 3 as mastery (expertise in using mental contents) and factor 4 as understanding other's mind (self-other monitoring and understanding). This factor structure is similar to Pedone et al. (2017).

\section{Internal consistency and test-retest reliability}

Cronbach's alpha for total MSAS scale was considered acceptable $(\alpha=.88)$. In the 4 factors the internal reliability was also considered acceptable (F1, $\alpha=.84,5$ items; F2, $\alpha$ $=.81,6$ items; F3, $\alpha=.74,4$ items and F4, $\alpha=.73$, 3 items).

Table 1. Factor structure according to the exploratory factor analysis on the 18-item MSAS.

\begin{tabular}{|c|c|c|c|c|c|}
\hline & F1 & F2 & F3 & $\mathrm{F} 4$ & Communalities \\
\hline Item 2 - UM_MON - ID2 & .813 & & & & .703 \\
\hline Item 1 - UM_MON - ID1 & .720 & & & & .633 \\
\hline Item 12 - DEC2 & & .764 & & & .670 \\
\hline Item 11 - DEC1 & & .751 & & & .625 \\
\hline Item 13 - DEC3 & & .637 & & & .560 \\
\hline Item $14-\mathrm{M} 1$ & & .473 & & & .342 \\
\hline Item $18-$ M5 & & & .786 & & .616 \\
\hline Item $16-\mathrm{M} 3$ & & & .724 & & .523 \\
\hline Item $15-\mathrm{M} 2$ & & & .695 & & .380 \\
\hline Item $17-M 4$ & & & .645 & & .518 \\
\hline Item 9 - UOM_MON_ID2__Dec2 & & & & .803 & .708 \\
\hline Item $10-$ UOM MON RV & & & & .773 & .712 \\
\hline
\end{tabular}

UM_MON - ID: Understanding Mind - Identification; UM_INT: Understanding Mind - Integration; UM_MON - REV1: Understanding Mind - Relenting Variables; UOM_MON_ID - De: Understanding Other's Mind - Identification; DEC: Decentering; UM_DIF: Understanding Mind - Differentiation; M: Mastery.

Table 2. Mean and standard deviations of the baseline and retest reliability with Spearman correlations and t-Student for total score and MSAS subscales $(n=22)$.

\begin{tabular}{|c|c|c|c|c|c|c|c|}
\hline & \multicolumn{2}{|c|}{ Test } & \multicolumn{2}{|c|}{ Retest } & \multirow{2}{*}{$\begin{array}{l}\mathrm{Sp} \\
r^{* *}\end{array}$} & \multicolumn{2}{|c|}{$t$ - test } \\
\hline & Mean & $(\mathrm{SD})$ & Mean & $(\mathrm{SD})$ & & $(d f=21)$ & $p$ \\
\hline MSAS & 4.042 & .539 & 4.204 & .436 & $.850 * *$ & 40.239 & .281 \\
\hline Understanding One's Own Mind & 3.401 & .612 & 3.522 & .480 & $.639 * *$ & 39.758 & .469 \\
\hline Mastery & 3.818 & .761 & 3.909 & .450 & $.832^{* *}$ & 34.110 & .633 \\
\hline Understanding Other's Mind & 4.000 & .545 & 4.136 & .686 & $.472^{*}$ & 40.980 & .451 \\
\hline
\end{tabular}


Temporal stability was assessed through a test-retest procedure. The sample for test-retest comprised 22 participants that were retested in a four weeks' interval (maximum deviation of 3 days). This sub-sample consisted of $6(27.3 \%)$ male, $16(72.7 \%)$ female, with a mean age of 29 years $(S D=$ 8.68 , ranged 19-58). Table 2 shows the means and standard deviations for test-retest assessments at the four factors tested. All factors showed adequate reliability according to temporal stability in the test-retest procedure.

\section{Construct validity}

Construct validity was tested through Pearson correlations between subscales and total scale. All correlations were statistically significant within metacognitive domains and total scale, ranging from medium $(r=.438)$ to high $(r=.860)-$ see Table 3.

\section{Convergent validity}

To our knowledge, there is no evidence of convergent validity between the MSAS with other assessment measures of metacognition as the Reflective Function (RF) interview and questionnaire (Fonagy, Steele, Steele, \& Target, 1997; Fonagy et al., 2016) and the MCQ (Cartwright-Hatton \& Wells, 1997). Therefore, the correlations between MSAS and MCQ were tested (Table 4). Overall, this analysis shows a weak

Table 3. Pearson correlations between domains and the total scale MSAS ( $n$ $=194)$.

\begin{tabular}{lllllll}
\hline & MSAS & UM & DEC - DIF & M & UOM \\
\hline MSAS & 1 & & & & & \\
Understanding One's Own Mind & $.818^{* *}$ & 1 & & & & \\
Decentering - Differentiation & $.860^{* *}$ & $.604^{* *}$ & 1 & & & \\
Mastery & $.796^{* *}$ & $.577^{* *}$ & $.551^{* *}$ & 1 & & \\
Understanding Other's Mind & $.673^{* *}$ & $.485^{* *}$ & $.447^{* *}$ & $.438^{* *}$ & 1
\end{tabular}

MSAS: Total score of MSAS; UM: Understanding One's Own Mind; UOM: Understand Other Mind; DEC-DIF: Decentering - Differentiation; M: Mastery. ${ }^{* *} p<.001$. negative correlation between the total score of MSAS and MCQ $(r=-.268, p<.05)$. Negative Beliefs correlated negatively with total score of MSAS $(r=-.373, p<.05)$, understanding one's own mind $(r=-.376, p<.05)$, decentering differentiation $(r=-.300, p<.05)$ and mastery $(r=-.394$, $p<.05)$. Thus, the need for control also was negatively correlated with understanding other's mind $(r=-.173, p$ $<.05)$.

\section{Divergent validity}

Pearson correlations between MSAS and IRI total scores and the subscales were used to test divergent validity. Between the total scores of MSAS and IRI, there were no statistically significant correlations. Moreover, there were no significant correlations between total score and sub-scales of MSAS and sub-scales of empathic concern and fantasy, with exception of a weak negative correlation between understand one's own mind and fantasy $(r=-.214, p<.05)$. However, personal discomfort correlated negatively with the total score of MSAS and sub-scales, while taking perspective correlate positively - see Table 5.

\section{Discriminant validity}

The sample was then divided into two subgroups according to the existence of clinical diagnosis through selfreports (considered as a sub-clinical group) and/or psychological counseling (this information was provided in the sociodemographic form). Two subsamples were computed, a clinical subsample $(N=26 ; M=32.15, D P=$ $12.04 ; 19-57)$ and the remaining participants without clinical diagnosis and psychological counseling were not included in the clinical group. Both samples matched for gender and age. The t-test statistic for independent samples was used to explore whether the MSAS was able to differentiate between these two groups. Table 6 shows that

Table 4. Pearson correlations between domains and sub-scales of MSAS and MCQ $(n=194)$

\begin{tabular}{|c|c|c|c|c|c|c|}
\hline & MCQ & PB & NB & $\mathrm{CC}$ & NC & CSC \\
\hline MSAS & $-.268^{* *}$ & -.121 & $-.373^{* *}$ & -.123 & $-.290^{* *}$ & .039 \\
\hline Understanding One's Own Mind & $-.352^{* *}$ & $-.185^{* *}$ & $-.376^{* *}$ & $-.212^{* *}$ & $-.283^{* *}$ & -.066 \\
\hline Decentering - Differentiation & $-.183^{*}$ & -.064 & $-.300^{* *}$ & -.022 & $-.191_{* *}^{*}$ & $.044^{*}$ \\
\hline Mastery & $-.285^{* *}$ & -.120 & $-.394^{* *}$ & -.122 & $-.299^{* *}$ & -.024 \\
\hline Understanding Other's Mind & -.069 & -.025 & -.134 & -.056 & $-.173^{* *}$ & $.166^{*}$ \\
\hline
\end{tabular}

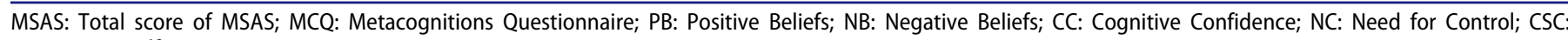
Cognitive Self-Conscious.

${ }^{* *} p<.001 ; * p<.05$.

Table 5. Pearson correlations between domains and subscales of MSAS and IRI $(n=194)$.

\begin{tabular}{|c|c|c|c|c|c|}
\hline & IRI & $\mathrm{EC}$ & $\mathrm{TP}$ & $\mathrm{F}$ & PD \\
\hline MSAS & -.079 & .041 & $.373^{* *}$ & -.135 & $-.344^{* *}$ \\
\hline Understanding One's Own Mind & -.131 & -.021 & $.297 * *$ & $-.214^{* *}$ & $-.224 * *$ \\
\hline Decentering - Differentiation & -.031 & .036 & $.316^{* *}$ & -.050 & $-.302^{* *}$ \\
\hline Mastery & -.101 & -.003 & $.345^{* *}$ & -.121 & $-.354^{* *}$ \\
\hline Understanding Other's Mind & -.057 & .0132 & $.307 * *$ & -.111 & $-.258^{* *}$ \\
\hline
\end{tabular}

MSAS: Total score of MSAS; IRI: Total score of Interpersonal Reactivity Index; EC: Empathic Concern, TP: Taking Perspective; F: Fantasy; Personal Discomfort. ${ }^{* *} p<.001$. 
Table 6. T-Test between non-clinical subsample $(n=26)$ and clinical subsample $(n=26)$.

\begin{tabular}{|c|c|c|c|c|c|c|}
\hline & \multicolumn{2}{|c|}{ Non-clinical Subsample } & \multicolumn{2}{|c|}{ Clinical Subsample } & \multicolumn{2}{|c|}{ T-Test } \\
\hline & Mean & $(\mathrm{SD})$ & Mean & $(S D)$ & $\mathrm{F}$ & Sig \\
\hline Total score of MSAS & 4.07 & .419 & 3.73 & .549 & 3.704 & $.000^{*}$ \\
\hline Understanding One's Own Mind & 4.13 & .537 & 3.79 & .730 & 6.426 & $.005^{*}$ \\
\hline Decentering - Differentiation & 3.61 & .778 & 3.50 & .692 & 5.360 & $.001^{*}$ \\
\hline Mastery & 3.90 & .570 & 3.55 & .861 & 5.530 & $.002^{*}$ \\
\hline Understanding Other's Mind & 4.26 & .427 & 3.87 & .627 & .395 & .113 \\
\hline
\end{tabular}

Table 7. Pearson correlations and stepwise hierarchical regression model of MCQ and MSAS total scores, sub-scales and CFQ ( $N=194)$

\begin{tabular}{|c|c|c|c|c|c|c|}
\hline & \multicolumn{6}{|c|}{ Cognitive Fusion } \\
\hline & $r^{* *}$ & $R^{2}$ & $R^{2^{*}}$ & $B$ & $t$ & $p$ \\
\hline$\overline{M C Q}$ & $.715^{* *}$ & .511 & .508 & .681 & 13.161 & .000 \\
\hline \multirow[t]{2}{*}{ MSAS } & $-.309 * *$ & .526 & .521 & -.127 & -2.451 & .015 \\
\hline & $r^{* *}$ & $R^{2}$ & $R^{2^{*}}$ & B & $t$ & $p$ \\
\hline Negative Beliefs & $.783^{* *}$ & .614 & .612 & .674 & 13.525 & .000 \\
\hline Cognitive Self-Conscious & $.501 * *$ & .639 & .635 & .127 & 2.388 & .018 \\
\hline Cognitive Confidence & $.472^{* * *}$ & .649 & .643 & .120 & 2.304 & .022 \\
\hline Positive Beliefs & $.462^{* *}$ & - & - & - & - & - \\
\hline \multirow[t]{2}{*}{ Need for Control } & $.587 * *$ & - & - & - & - & - \\
\hline & $r^{* *}$ & $R^{2}$ & $R^{2^{*}}$ & $B$ & $t$ & $p$ \\
\hline Mastery & $-.360 * *$ & .130 & .183 & -.284 & -3.437 & .001 \\
\hline Understanding One's Own Mind & $-.344^{* *}$ & .157 & .228 & -.265 & -3.125 & .002 \\
\hline Understanding Other's Mind & -.078 & .180 & .167 & .175 & 2.269 & .024 \\
\hline Decentering - Differentiation & $-.230 * *$ & - & - & - & - & - \\
\hline
\end{tabular}

MSAS: Total score of MSAS; MCQ; Total score of MCQ.

${ }^{*} p<.001$.

only understand other's mind $(p>.05)$ did not differentiated the two subsamples.

\section{Metacognition and cognitive fusion}

We intend to explore the relationship between metacognition and cognitive fusion, a construct from ACT (Hayes et al., 2011) and the relationship between metacognition and meta-beliefs from SREF (Wells, 2000).

Table 7 describes the correlations between metacognitive functions (MSAS), metacognitive contents (MCQ), and cognitive fusion (CFQ). On one hand, we found positive moderate to strong correlations between MCQ total score and sub-scales, and with CFQ. On the other hand, we found negative weak correlations between the MSAS with the MCQ total score and sub-scales, and with the CFQ.

Regression analyses shows that MCQ and MSAS may predict cognitive fusion variance throught different hierarchical models. MCQ predicts cognitive fusion with compounds such negative beliefs $(b=.674, p=.000)$, cognitive self-conscious $(b=.127, p=.018)$ and cognitive confidence $(b=$ $.120, p=.022)$. This model explained $64 \%$ of the variance. MSAS hierarchical model showed three predictors with mastery $(b=-.284, p=.000)$ as the most significant predictor.

Following these results, we aimed to explore a combined multi-compound hierarchical model through a stepwise regression analysis with MSAS and MCQ subscales. A significant composite model with four predictors was found accounting for $65 \%$ of the variance of cognitive fusion. The model was composed by the following predictors: negative beliefs $(b=.629, p=.000)$, cognitive self-conscious $(b=.147$, $p=.007)$ cognitive confidence $(b=.117, p=.025$ and mastery $(b=-.094, p=.048)$.

\section{Discussion}

This study aimed to explore the psychometric properties of the MSAS in the Portuguese population and the associations between metacognition and related constructs. The exploratory factorial analysis showed a latent structure of 4 factors, such as factor 1 - understanding one's own mind (self-self reflexivity), factor 2 - decentering-differentiation (critical distance), factor 3 - mastery (expertise in using mental contents) and factor 4 - understanding other's mind (self-other monitoring and understanding).

This factor structure is the same as the study by Pedone et al. (2017), with one exception: Factor 2 concerning decentering-differentiation was composed with one item from mastery. Item 14 "I can deal with the problem voluntarily imposing or inhibiting a behavior on myself", may also be interpreted as representing a distancing skill, because, individuals need to distance themselves to observe their problems and to choose how to act on them. Thus, this item may also reflect a coping strategy of behavioral inhibition. Moreover, Pedone et al. (2017), reported that the binomial decentering-differentiation may be a part of critical distance, because it refers to the ability to distance from internal representations to describe the desires and intentions of others Therefore, this combination is different from the original, but it may be theoretically acceptable (Dimaggio et al., 2007). However, we did not rename factor 2 , because it did not affect the factor conceptualization. In future studies, it 
will be interesting to see if the same factor structure is replied.

The internal consistency of the MSAS scales, test-retest and the construct validity was adequate. We have explored the association between the metacognitive functions (MSAS) and the content (MCQ), with negative associations between most of the sub-functions. Negative correlations between negative beliefs, need for control and MSAS sub-scales showed that non-adaptive views of the self and control are associated with lower metacognitive skills. This may be evidence of convergent validity of MSAS, which is a selfreported scale based on adaptive dimensionality of the items. This result may also have some clinical implications. Furthermore, factor 4 understanding other's mind had the lowest correlations. This may be due to poor variability in the sample data or simply because the focus of meta-beliefs is in self-self reflexivity and not on the self-other identification/differentiation.

Besides, we have found adequate divergent validity. The MSAS seems to be measuring the purposed metacognitive structure according to this analysis. This is suggested by the absence of an association between empathic concern and fantasy from IRI (despite the negative correlation between understand one's own mind and fantasy). This shows that MSAS is measuring distinct types of mental processes, such as metacognitive functions in spite of empathy or fantasy/ creative processes. However, we also find evidence of convergent validity due to positive correlations between MSAS and taking perspective, and negative correlations with personal discomfort from IRI.

Discriminant validity was true to the total score of MSAS and three subdomains. Mean values were higher on clinical subsample than non-clinical subsample and this difference was statistical significant. These preliminar results may show that MSAS (self-self reflexivity, decentering-differentiation, and mastery), may discriminate clinical from non-clinical populations. Understanding other's mind did not differentiate the two sub-samples. This may be due to the small sample size and to the fact that the sub-clinical sample derived from single self-report questions and not from a comprehensive instrument to assess psychopathology. Despite these limitations, the results suggest that the MSAS may be a valid and reliable instrument to assess metacognitive functions.

\section{Psychotherapeutic and clinical neuropsychological implications}

Regarding clinical implications of the relationship between metacognition and meta-beliefs, some considerations can be made. Our results show that metacognitive skills according to MMFM are negatively associated with negative beliefs and need for control. According to Wells (2000), negative metabeliefs are associated with rumination and preoccupation which facilitates anxiety symptomatology. With this in mind, we stated that metacognitive stimulation may be complementary to anxiety exposure methods. Notably, cognitive self-consciousness showed to be positively associated with decentering-differentiation and understanding other's mind.
Being self-conscious may be viewed as an adaptive mental stance which is associated with good metacognitive skills. Thus, these preliminary results may support previous definitions of meta-awareness as a decentering process (Bernstein et al., 2015).

Taking perspective from IRI was positively correlated with all MSAS domains, which may support the previous assumptions where taking perspective in social contexts depends on how one is able to identify and describe other feelings and intentions, from alternatives points of views rather than his own personal one (Dimaggio \& Lysaker, 2010; Dimaggio et al., 2007). Furthermore, taking perspective may reflect an adequate metacognitive functioning in which processes of self-self, selfother, decentering-differentiation, and mastery, are operating appropriately to support a mental shifting ability from one's own world view (Dimaggio et al., 2015, Morris \& Mansell, 2018). Another clinical aspect that emerged from our data was the negative correlation between personal discomfort and all metacognitive domains from MSAS. Fundamentally, this shows that a lack of decentering-differentiation (critical distance) and mastery (higher negative correlation factors with personal discomfort) in coping with one's own states of mind, beliefs, intentions, and feeling, may lead to dysfunctional experiences and distressful private events (Dimaggio et al., 2007; Hayes et al., 2011). Thus, the lack of soothing and internal coping skills may lead to experiential avoidance which in turn, may develop cognitive fusion (Hayes et al., 2011).

Cognitive fusion is associated with metacognition, either from a functional perspective (MSAS) or in terms of content (MCQ). However, we have found that cognitive fusion is more associated with metacognitive content than metacognitive functions, namely, negative beliefs, cognitive selfconsciousness, and need to control (higher correlations with cognitive fusion). To our knowledge, this is a new finding which may have some clinical implications. Cognitive fusion is the automatic effects of verbal thought content in controlling behavior (Hayes et al., 2011). When symbolized in words, beliefs tend to take the form of verbalizations, such as "I am inadequate" or "The world is against me". According to Hayes et al. (2011), this sub-process develops from the inflexibility of verbal rules that can manifest in terms of dysfunctional beliefs has a result of experiental avoidance. Therefore, it is expected that cognitive fusion was more correlated with meta-beliefs than metacognitive functions such as understanding other's mind. Although, metacognitive functions were negatively correlated with cognitive fusion which implies some clinical considerations. Our data shows that cognitive fusion may play a role in some metacognitive functions, namely: self-self reflexivity, decenteringdifferentiation and mastery.

Regarding the first factor, to understand self-subjective experience it's required a set of skills as identification, differentiation and integration of internal phenomena (Dimaggio et al. 2007). These processes are similar to the metacognitive model of meta-awareness and identification of internal experience (Bernstein et al., 2015). One could argue that selfself reflexivity metacognitive domain reflects the experiential self and the reflexive self, where healthy individuals may 
swing/alternate adaptatively from one metacognitive domain to another according with internal and external stimuli. The experiential self may be viewed as the mental position where individual's think, behave and feel the experiential cycle in first person in a full sensorial mode. Whereas the reflexive self, may be viewed as the mental position where individuals mentaly "step back" and reflect about personal experiences which support meaning-making and access to metamemory (Grainger, Williams, \& Lind, 2014). It is the optimal balance between these two metacognitive modes (shifting mental abilities) that may faciliate cognitive-affective processing, related to self-content. Thus, this is similar to the concept of psychological needs satisfaction, where it is also the ability to swing between dialectical polarities of psychological needs (e.g., control-cooperation), that underly adaptative mental functioning (Faustino \& Branco, 2019; Vasco, Conceição, Silva, Ferreira, \& Vaz-Velho, 2018). In this sense, it is the ability to shift and adapt internal dispositions to contextdepended demands that underly the notion of psychological flexibility, which is a fundamental aspect of mental health (Kashdan \& Rottenberg, 2010).

In this sense, and according to our data an individual with higher levels of cognitive fusion may have poor abilities on the identification and differentiation (cognitive-affective) of their own mental states, because he or she has difficulties to swing between the experiential self and the reflexive self. Thus, Bernstein et al. (2015), states that cognitive fusion facilitates an increased reactivity to thought content, because of the lacking of critical distance from self-distressful subjective experiences (disentangle atention from experiental self to reflexive self to cognitive and affective processing). Individuals tend to get caught in their own internal verbal loop without the awareness and disidentification needed to separate from internal painful experience. Therefore, the more an individual is "fused" with his/her thoughts, the lower is the metacognitive ability to describe self and others states of mind, feelings and intentions, and also to manipulate one's own mental contents adequately. Nevertheless more research is needed to explore the relationships between experiential self and reflexive self as well as the associated neurocognitive processes and mental functions.

Factor 2, named decentering-differentiation showed a negative correlation with cognitive fusion, which means that cognitive fusion has a negative impact on taking a critical distance, decentering and differentiation from one's self to understand others mind from their own perspective. This is a core issue in the present work. Decentering and differentiation have a long history in psychotherapy and clinical neuropsychology and may play an important role in mental health (Bernstein et al., 2015; Bernstein, Hadash, \& Fresco, 2019). The ability to shift from one's own internal subjective experience to other's is a process that is described through different concepts (e.g., detached mindfulness, cognitive distancing, decentering).

The metacognitive model of decentering from Bernstein et al. (2015), states that cognitive fusion is related to reactivity to thought content. However, according to our data, cognitive fusion may also be related with meta-awareness and identification of internal experience, because, it is also related with the factor 1 (self-self reflexivity), which also imply these two processes. Therefore, cognitive fusion may be associated with the underlying process of meta-awareness, disidentification and reactivity to thought content, which in turns decreases the ability of decentering-differentiation. In this sense, individuals may have difficulties on the identification of the others of cognitions, beliefs and feelings, from others perspectives, leading them to poor social cognition skills and symptomatology (Bo et al., 2015; Dimaggio \& Lysaker, 2010).

Factor 3, mastery of MSAS is negatively associated with cognitive fusion. Which implies that individuals with excessively verbal ruled behavior, lack the internal flexibility to cope adequately with mental contents such as thoughts, beliefs, needs and feelings (Dimaggio et al., 2015; Hayes et al., 2011; Morris \& Mansell, 2018). Semerari et al., (2003, 2007), states that mastery is a metacognitive ability that involves maturity and flexibility to modification of perspectives, which imply the ability to not only to identify and distance oneself from private experience but also to manage it adequately. Also, it is expected that adaptive mastery relies on others metacognitive functions. Therefore, mastery may be viewed as the optimal ability to use or manipulare mental contents (e.g., cognitions, beliefs, desires, needs), from selfself reflexivity, self-other and from decentering-differentiation to understand one's own internal word, self soothe, navigate on the environment and to solve interpersonal problems (Pedone et al., 2017; Semerari et al., 2003).

Moreover, Lysaker et al. (2008), stated that individuals with lesions in the prefrontal cortex decline in their metacognitive abilities, specifically through the orbitofrontal (Gallese et al., 1996) and lateral prefrontal cortex (Fleming \& Dolan, 2012) that may underlie metacognitive skills. Given the association between metacognitive content (MCQ) with cognitive fusion, it is possible that these structures may also underly cognitive fusion, while executive functions (cognitive flexibility, working memory, inhibition) play a role between metacognition and cognitive fusion. However, this hypothesis needs to be deeper understood in a future study.

Metacognitive assessment may be an asset to clinical psychology and neuropsychological interventions, because it may give tools to clinicians to better understand the patient and his/her level of insight regarding the self and others. Self-awareness in psychopathology and neurological patients is a problem and is a barrier to treatment improvement (Dimaggio \& Lysaker, 2010, Lysaker et al., 2019). Directing intervention at metacognition may lead to symptom reduction in some psychopathological conditions as borderline personality disorder (Maillard et al., 2017), social anxiety (Nordahl \& Well, 2018) and psychosis (Lysaker et al., 2018). Self-awareness, self-reflection and insight may be promoted through metacognitive interventions focused on self-self, selfother, decentering-differentiation and mastery, which is correlated with better therapy outcomes (Lysaker \& Lysaker, 2008; Lysaker et al., 2019; Van Donkersgoed, De Jong, \& Pijnenborg, 2016). Therefore, we stated that 
psychotherapeutic intervention and neuropsychological rehabilitation focused on metacognition may be an asset in a wide range of patients.

Besides, Semerari et al. (2003) stated that: (1) metacognitive functions have a modular structure; (2) for each type of psychopathological condition there should be a different metacognitive profile and (3) to have successful interventions (psychotherapy or clinical neuropsychology), they should involve improvements in some deficient metacognitive sub-functions. Our results support the first statement, due to the factorial structure which is similar to results from Pedone et al. (2017).

In the future, other studies may help to support psychometric properties of MSAS, such as confirmatory factor analysis, rash analysis and/or studies with clinical samples. Thus, a mixed statistical approach could also be considered as an asset (Faustino et al., 2019). Also, more studies are needed to deepen our understanding about the relationships between metacognition, on one hand, with other relevant clinical psychology constructs, such as, early maladaptive schemas, states of mind or interpersonal dysfunctional cycles (Dimaggio et al., 2015; Faustino \& Branco, 2019). On the other hand, more studies are needed to explore the relationships between metacognition and neurocognitive constructs, such as, cognitive flexibility, abstract reasoning, inhibition, working memory, decision making or speed of processing.

One limitation of our study is that responses to MSAS can be biased by social desirability, due to having all the positive responses (e.g., all item are in the positive form), leading individuals to report better metacognitive abilities than the real ones. Therefore, we consider that some reverse items could contribute to reducing such bias. The sample size in the test-retest assessment was small. Also, the majority of participants are female which may have also affected the representativeness of the sample. Finally, we consider that the metacognitive abilities must also be evaluated by performance tests, to have a more ecological assessment of metacognition while contributing to overcome the bias of self-reports.

In sum, MSAS may be a reliable instrument to assess metacognition, but further studies are required to provide consistent evidence of MSAS validity and reliability in the community samples and clinical population.

\section{Acknowledgments}

We wish to thank Dr. Carcione for the permission to translate the Metacognition Self-Assessment Scale to Portuguese language.

\section{ORCID}

Bruno Faustino (iD http://orcid.org/0000-0002-7948-1622 António Branco Vasco iD http://orcid.org/0000-0002-2174-7360 Jorge Oliveira (D) http://orcid.org/0000-0002-3467-4981 Paulo Lopes (iD http://orcid.org/0000-0002-3128-1365 Isabel Fonseca (iD) http://orcid.org/0000-0002-1965-2207

\section{References}

Bártolo-Ribeiro, R., Simões, M. R., \& Almeida, L.S. (2016). Metacognitive awareness inventory (MAI): Adaptation and validation of Portuguese version. Revista Iberoamericana de Diagnostico y Evaluacion Psicologica, 2(42), 143-159. doi:10.21865/RIDEP42-145

Bateman, A., Bolton, R., \& Fonagy, P. (2013). Antisocial personality disorder: A metalizing framework. Focus - FOCUS, 2, 178-186. doi: 10.1176/appi.focus.11.2.178

Bernstein, A., Hadash, Y., \& Fresco, D. M. (2019). Metacognitive processes model of decentering: Emerging methods and insights. Current Opinion in Psychology, 28, 245-251. doi:10.1016/j.copsyc.2019.01.019

Bernstein, A., Hadash, Y., Lichtash, Y., Tanay, G., Shepherd, K., \& Fresco, D. M. (2015). Decentering and related constructs: A critical review and metacognitive processes model. Perspectives on Psychological Science, 10(5), 599-617. doi:10.1177/1745691615594577.

Bo, S., Kongerslev, M., Dimaggio, G., Lysaker, P. H, \& Abu-akel, A. (2015). Metacognition and general functioning inpatients with schizophrenia and a history of criminal behaviour. Psychiatry Research, 225(3), 247-253. doi:10.1016/j.psychres.2014.12.034

Brunet-Gouet, E., Achim, A. M., Vistoli, D., Passerieux, C., HardyBaylé, M.-C., \& Jackson, P. L. (2011). The study of social cognition with neuroimaging methods as a means to explore future directions of deficit evaluation in schizophrenia. Psychiatry Research, 190(1), 23-31.

Carcione, A., Dimaggio, G., Conti, L., Fiore, D., Nicolò, G., \& Semerari, A. (2010). Metacognition Assessment Scale v. 4.0. Unpublished manuscript, Rome.

Cartwright-Hatton, S., \& Wells, A. (1997). Beliefs about worry and intrusions: The Meta-Cognition Questionnaire and its correlates. Journal of Anxiety Disorders, 11(3), 279-296.

Davis, M. H. (1980). A multidimensional approach to individual differences in empathy. JSAS Catalog of Selected Documents in Psychology, 10, 85-103.

Dimaggio, G., \& Lysaker, P. H. (2010). Metacognition and severe adult mental disorders: From basic research to treatment. London, UK: Routledge.

Dimaggio, G., Montano, A., Popolo, R., \& Salvatore, G. (2015). Metacognitive interpersonal therapy for personality disorders: A treatment manual. London, UK: Routledge.

Dimaggio, G., Semerari, A., Carcione, A., Nicolò, G., \& Procacci, M. (2007). Psychotherapy of personality disorders: Metacognition, states of mind and interpersonal cycles. London, UK: Routledge.

Dinis, A., \& Pinto-Gouveia, J. (2011). Estudo das características psicométricas da versão portuguesa do Questionário de Metacognições - Versão reduzida e do Questionário de Meta-preocupação (Study of the psychometric characteristics of the Portuguese version of the Metacognition Questionnaire - short version). Psychologica, 54, 281-307. doi:10.14195/1647-8606_54_11

Faustino, B., \& Branco, A. B. (2019). Schematic functioning, interpersonal dysfunctional cycles and cognitive fusion in complementary paradigm perspective: Analysis of a clinical sample. Journal of Contemporary Psychotherapy, 14, 1-9. doi:10.1007/s10879-01909422-x

Faustino, B., Lopes, P., Oliveira, J., Campaioli, G., Rondinone, M., Bomfim, H., \& Germano, L. (2019). Psychometric and rash analysis of the UCLA loneliness scale-16 in a Portuguese sample of older adults. Psychological Studies, 64(2), 140. doi:10.1007/s12646-01900483-5

Faustino, B., Oliveira, J., \& Lopes, P. (2019). Diagnostic precision of the Wisconsin Card Sorting Test in assessing cognitive deficits in substance use disorders. Applied Neuropsychology: Adult, 1-8. doi:10. 1080/23279095.2019.1607737

Fleming, S. M., \& Dolan, R. J. (2012). The neural basis of metacognitive ability. Philosophical Transactions of the Royal Society B: Biological Sciences, 367(1594), 1338-1349. doi:10.1098/rstb.2011.0417

Fonagy, P., Gergely, G., Jurist, A., Elliot, L., \& Target, M. (2002). Affect regulation, mentalisation and the development of the self. New York, NY: The Other Press. 
Fonagy, P., Luyten, P., Moulton-Perkins, A., Lee, Y.-W., Warren, F., Howard, S., ... Lowyck, B. (2016). Development and validation of a self-report measure of mentalizing: The reflective functioning questionnaire. PLoS One, 11(7), e0158678. doi:10.1371/journal.pone. 0158678

Fonagy, P., Steele, M., Steele, H., \& Target, M. (1997). Reflective-functioning manual, version 4.1, for application to adult attachment interviews. London: University College London.

Frith, C., \& Frith, U. (2006). The neural basis of mentalizing. Neuron, 50(4), 531-534. doi:10.1016/j.neuron.2006.05.001

Gallese, V., Fadiga, L., Fogassi, L., \& Rizzolatti, G. (1996). Action and cognition in the premotor cortex. Brain, 119(2), 593-609. doi:10. 1093/brain/119.2.593

Gillanders, D. T., Bolderston, H., Bond, F. W., Dempster, M., Flaxman, P. E., Campbell, L., ... Remington, R. (2014). The development and initial validation of The Cognitive Fusion Questionnaire. Behavior Therapy, 45(1), 83-101. doi:10.1016/j.beth.2013.09.001

Grainger, C., Williams, D. M., \& Lind, S. E. (2014). Metacognition, metamemory, and mindreading in high-functioning adults with autism spectrum disorder. Journal of Abnormal Psychology, 123(3), 650-659. doi:10.1037/a0036531

Gumbley, A. (2011). Metacognition, affect regulation and symptom expression: A transdiagnostic perspective, Psychiatry Resrarch, 190, 72-78. DOI: 10.1016/j.psychres.2011.09.025

Harder, S., \& Folke, S. (2012). Affect regulation and metacognition in psychotherapy of psychosis: An integrative approach. Journal of Psychotherapy Integration, 22(4), 330-343. doi:10.1037/a0029578

Hayes, S. C., Strosahl, K. D., \& Wilson, K. G. (2011). Acceptance and commitment therapy: The process and practice of mindful change (2nd ed.). New York, NY: Guilford Press.

Kashdan, T. N., \& Rottenberg, J. (2010). Psychological flexibility as a fundamental aspect of health. Clinical Psychology Review, 30(7), 865-878. doi:10.1016/j.cpr.2010.03.001

Lezak, M. D. (2015). Neuropsychological assessment (5th ed.). New York, NY: Oxford University Press.

Limpo, T., Alves, R. A., \& Castro, S. L. (2010). Medir a empatia: Adaptação portuguesa do Índice de Reactividade Interpessoal. Laboratório de Psicologia, 8(2), 171-184. doi:10.14417/lp.640

Lories, G., Dardenne, B., \& Yzerbyt, V. Y. (1998). From social cognition to metacognition. In V. Y. Yzerbyt, G. Lories, \& B. Dardenne (Eds.), Metacognition: Cognitive and social dimensions (pp. 1-15). London, UK: Sage.

Lucangeli, D., Cornoldi, C., \& Tellarini, M. (1998). Metacognition and learning disabilities in mathematics. In T. E. Scruggs \& M. A. Mastropieri (Eds.), Advances in learning and behavioral disabilities (Vol. 12, pp. 219-244). Atlanta, GA: Elsevier Science/JAI Press.

Lysaker, P. H., Hamm, J. A., Vohs, J., Kukla, M., Pattison, M., Leonhardt, B., \& Lysaker, J. T. (2018). Understanding the course of self-disorders and alterations in self-experience in schizophrenia: Implications from research on metacognition. Current Psychiatry Reviews, 14(3), 160. doi:10.2174/1573400514666180816113159

Lysaker, P. H., Kukla, M., Vohs, J. L., Schnakenberg Martin, A. M., Buck, K. D., \& Hasson Ohayon, I. (2019). Metacognition and recovery in schizophrenia: From research to the development of metacognitive reflection and insight therapy. Journal of Experimental Psychopathology, 10(1), 204380871881499. doi:10.1177/2043808718814992

Lysaker, P. H., \& Lysaker, J. T. (2008). Schizophrenia and alterations in self-experience: A comparison of 6 perspectives. Schizophrenia Bulletin, 36(2), 331-340. doi:10.1093/schbul/sbn077

Lysaker, P. H., Warman, D. M., Dimaggio, G., Procacci, M., LaRocco, V. A., \& Clark, L. K. (2008). Metacognition in schizophrenia associations with multiple assessments of executive functions. The Journal of Nervous and Mental Disease, 196(5), 384-389. doi:10.1097/NMD. Ob013e3181710916

Maillard, P., Dimaggio, G., de Roten, Y., Berthoud, L., Despland, J.-N., \& Kramer, U. (2017). Metacognition as a predictor of change in the treatment for borderline personality disorder: A preliminary pilot study. Journal of Psychotherapy Integration, 27(4), 445. doi:10.1037/ int0000090
Morris, L., \& Mansell, W. (2018). A systematic review of the relationship between rigidity/flexibility and transdiagnostic cognitive and behavioral processes that maintain psychopathology. Journal of Experimental Psychopathology, 9(3), 204380871877943. doi:10.1177/ 2043808718779431

Nemiah, J. C., Freyberger, H., \& Sifneos, P. E. (1976). Alexithymia: A view of the psychosomatic process. In O. W. Hill (Ed.), Modern trends in psychosomatic medicine (Vol. 3, pp. 430-439). London, UK: Butterworths.

Nicolò, G., Dimaggio, G., Popolo, R., Carcione, A., Procacci, M., Hamm, J., ... Lysaker, P. H. (2012). Associations of metacognition with symptoms, insight, and neurocognition in clinically stable outpatients with schizophrenia. Journal of Nervous Mental Disease, 200, 644-647. doi:10.1097/NMD.0b013e31825bfb10

Nordahl, H., \& Well, A. (2018). Metacognitive therapy for social anxiety disorder: An A-B replication series across social anxiety subtypes. Frontiers in Psychology, 9, 540. doi:10.3389/fpsyg.2018.00540

Pedone, R., Semerari, A., Riccardi, I., Procacci, M., Nicolò, G., \& Carcione, A. (2017). Development of a scale-self report measure of metacognition: The metacognition self-assessment scale (MSAS) Instrument description and factor structure. Clinical Neuropsychiatry, 3(14), 185-194.

Pellecchia, G., Moroni, F., Carcione, A., Colle, L., Dimaggio, G., Nicolò, G., ... Semerari, A. (2015). Metacognition Assessment Interview: Instrument description and factor structure. Clinical Neuropsychiatry, 12(6), 157-165.

Pestana, M., \& Gageiro, J. (2008). Análise de dados para Ciências Sociais - A complementaridade do SPSS (5a ed.). Lisboa, Portugal: Edições Sílabo.

Pinto-Gouveia, J., Dinis, A., Gregório, S., \& Pinto, P. (2013). Questionário de Fusão Cognitive: Versão Portuguesa -. (Cognitive Fusion Questionnaire) - unpublished.

Praszkier, R. (2016). Empathy, mirror neurons and SYNC. Mind \& Society, 15(1), 1-25. doi:10.1007/s11299-014-0160-x

Premack, D., \& Woodruff, G. (1978). Does chimpanzee have a theory of mind? Behavioral and Brain Sciences 1, 4, 515-526. doi:10.1017/ S0140525X00076512

Raposo, A., Vicens, L., Clithero, J. A., Dobbins, I. G., \& Huettel, S. A. (2010). Contributions of frontopolar cortext to judgements about self, others and relations. Social Cognitive and Affective Neuroscience, $3,260-269$.

Schraw, G., \& Dennison, R. S. (1994). Assessing metacognitive awareness. Contemporary Educational Psychology, 19, 460-475.

Semerari, A., Carcione, A., Dimaggio, G., Falcone, M., Nicolò, G., Procacci, M., \& Alleva, G. (2003). How to evaluate metacognitive functioning in psychotherapy? The metacognition assessment scale and its applications. Clinical Psychology \& Psychotherapy, 10, 238-261. doi:10.1002/cpp.362

Semerari, A., Carcione, A., Dimaggio, G., Nicolò, G., \& Procacci, M. (2007). Understanding minds: Different functions and different disorders? The contribution of psychotherapy research. Psychotherapy Research, 17(1), 106-119. doi:10.1080/10503300500536953

Semerari, A., Cucchi, M., Dimaggio, G., Cavadini, D., Carcione, A., Bottelli, V., ... Smeraldi, E. (2012). The development of the metacognition assessment interview: Instrument description, factor structure and reliability in a nonclinical sample. Psychiatry Research, 200, 890-895. doi:10.1016/j.psychres.2012.07.015

Shimamura, A. P. (2000). Toward a cognitive neuroscience of metacognition. Consciousness and Cognition, 9(2), 313-323. doi:10.1006/ ccog. 2000.0450

Solbakken, O. A., Hansen, R. S., Havik, O. E., \& Monsen, J. T. (2012). Affect integration as a predictor of change: Affect consciousness and treatment response in open-ended psychotherapy. Psychotherapy Research, 22(6), 656-672. doi:10.1080/10503307.2012. 700871

Van Donkersgoed, R., De Jong, S., \& Pijnenborg, G. (2016). Metacognitive reflection and insight therapy (MERIT) with a patient with persistent negative symptoms. Journal of Contemporary Psychotherapy, 46(4), 245-253. doi:10.1007/s10879-016-9333-8 
Vasco, A. B., Conceição, N., Silva, A. N., Ferreira, J. F., \& Vaz-Velho C. (2018). O (meta)modelo de complementariedade paradigmática (MCP). In I. Leal (Ed.), Psicoterapias. Lisbon, Portugal: Pactor. [Paradigmatic Complementarity Metamodel].

Wells, A. (2000). Emotional disorders and metacognition: Innovative cognitive therapy. Chichester, UK: Wiley.
Wells, A., \& Cartwright-Hatton, S. (2004). A short form of the metacognitions questionnaire: Properties of the MCQ-30. Behaviour Research and Therapy, 42(4), 385-396.

Wells, A., \& Mathews, G. (1994). Attention and emotion. A clinical perspective. Hove, UK: Lawrence Erlbaum \& Associates. doi:10.1016/ S0005-7967(03)00147-5 